\title{
Identification of Quantitative Trait Loci for Resistance to Southern Leaf Blight and Days to Anthesis in Two Maize Recombinant Inbred Line Populations
}

\author{
P. J. Balint-Kurti, J .C. Zwonitzer, M. E. Pè, G. Pea, M. Lee, and A. J. Cardinal
}

First and second authors: U.S. Department of Agriculture-Agricultural Research Service (USDA-ARS) Plant Science Research Unit and Department of Plant Pathology, North Carolina State University, Raleigh 27695-7616; third and fourth authors: Department of Biomolecular Sciences and Biotechnology, Università degli Studi di Milano, Milano, Italy; fifth author: R. F. Baker Center for Plant Breeding, Department of Agronomy, Iowa State University, Ames 50011; and sixth author: North Carolina State University, Department of Crop Science, Raleigh 27695-7620.

Accepted for publication 11 October 2007.

\begin{abstract}
Balint-Kurti, P. J., Zwonitzer, J. C., Pè, M. E., Pea, G., Lee, M., and Cardinal, A. J. 2008. Identification of quantitative trait loci for resistance to southern leaf blight and days to anthesis in two maize recombinant inbred line populations. Phytopathology 98:315-320.

The genetic architecture underlying resistance in maize to southern leaf blight (SLB) caused by Cochliobolus heterostrophus race $\mathrm{O}$ is not well understood. The objective of this study was to identify loci contributing to SLB resistance in two recombinant inbred line populations and to compare these to SLB resistance loci in other populations. The two populations used were derived from crosses between maize inbred lines

population-186 lines). They were evaluated for SLB resistance and for days from planting to anthesis (DTA) in 2005 and 2006. Two replications arranged as randomized complete blocks were assessed in each year for each population. Entry mean heritabilities for disease resistance were high for both populations ( 0.876 and 0.761 , respectively). Quantitative trait loci (QTL) for SLB resistance were identified in bins 3.04 (two QTL), 6.01, and 8.05 in the HB population and in bin 2.07 in the BB population. No overlap of DTA and SLB resistance QTL was observed, nor was there any phenotypic correlation between the traits. A comparison of the results of all published SLB resistance QTL studies suggested that bins 3.04 and 6.01 are 'hotspots' for SLB resistance QTL.
\end{abstract} H99 and B73 (HB population-142 lines) and between B73 and B52 (BB
Cochliobolus heterostrophus (Drechs.) Drechs. (anamorph = Bipolaris maydis [Nisikado] Shoemaker; synonym $=$ Helminthosporium maydis Nisikado) is a necrotrophic plant pathogen and the causal agent of southern leaf blight (SLB) of maize (Zea mays L.). This disease is frequently found in hot, humid maize-growing areas worldwide. It is a significant problem in the southern subtropical maize-growing regions of the United States and parts of India, Africa, and Western Europe. It can cause grain yield losses of $40 \%$ or more, though this is rare $(6,13,16)$.

Most identified genetic resistance to SLB is quantitative and can be additive or recessive in effect $(3,5,19,22)$. The recessive gene rhm confers almost complete SLB resistance in pre-anthesis growth stages and a partial level of resistance post-anthesis. It has been mapped to the distal end of the short arm of chromosome six (bin 6.00) (32).

To date, studies have been published on mapping quantitative trait loci for field resistance to SLB in maize from populations derived from the following five crosses: B73/Mo17, B73/NC250A, ADENT/B73, B104/NC300, and a highland tropical inbred/lowland tropical inbred $(2-4,10,21)$. In addition, one study identified SLB resistance quantitative trait loci (QTL) in juvenile maize plants in a population derived from a B73/Mo17 cross (1). For the highland tropical inbred/lowland tropical inbred population a single QTL was identified in a single environment (21), while the

Corresponding author: P. J. Balint-Kurti

E-mail address: Peter.Balint-Kurti@ars.usda.gov

doi:10.1094/PHYTO-98-3-0315

This article is in the public domain and not copyrightable. It may be freely reprinted with customary crediting of the source. The American Phytopathological Society, 2008. study assessing the B73/NC250A and ADENT/B73 populations was completed before molecular markers spanning the genome were widely available (4) and substantial areas of the genome were not surveyed. Therefore, the range of germplasm that has been surveyed for SLB resistance QTL is still relatively limited. Here we report on the identification of SLB resistance and days to anthesis (DTA) QTL in two additional recombinant inbred line (RIL) populations derived from H99/B73 and B73/B52 crosses. We also compare positions of all the SLB QTL identified to date in order to better understand the genetic architecture underlying this trait.

\section{MATERIALS AND METHODS}

Plant materials and genotypic information; H99/B73 population (henceforth referred to as the HB population). Phenotypic data were collected from a mapping population comprised of $142 \mathrm{~F}_{6: 7}$ RIL derived from the cross of maize inbred lines $\mathrm{H} 99$ (resistant parent) and B73 (susceptible parent) (15). A map constructed using genotypic information at 158 restriction fragment length polymorphism (RFLP) and simple sequence repeats (SSR) marker loci (14) was used for this study. The total map length was 2,087 cM with an average distance between loci $14.1 \mathrm{cM}$.

B73/B52 population (henceforth referred to as the BB population). Phenotypic data were collected from a mapping population comprised of $186 \mathrm{~F}_{6: 8}$ RIL derived from the cross of maize inbred lines B73 and B52 (9). Both of these lines were relatively susceptible to SLB with B52 being slightly more SLB resistant than B73. A map constructed using genotypic information at 157 RFLP and SSR marker loci was used $(8,9)$. The total map length was $1,619 \mathrm{cM}$ with an average distance between loci of $11 \mathrm{cM}$. 
A

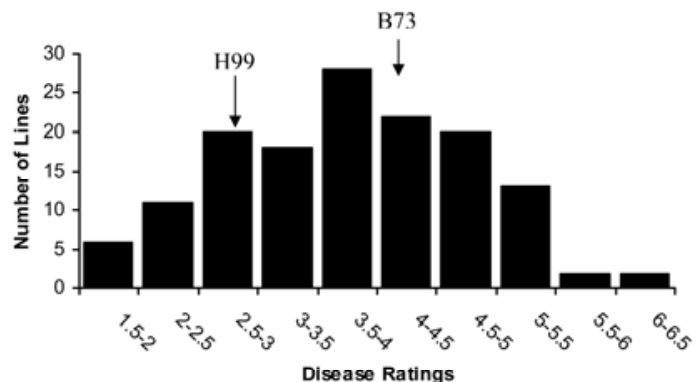

B
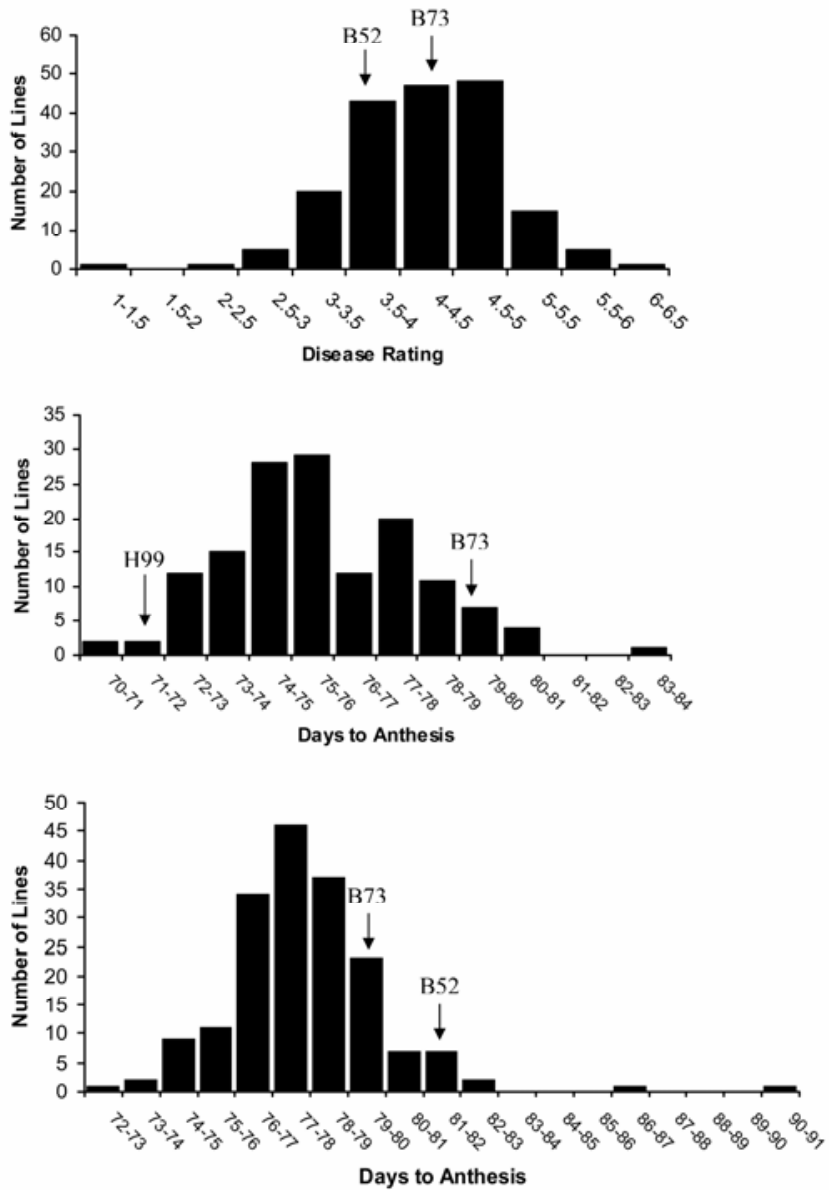

Fig. 1. The distribution of average scores for weighted mean disease (WMD) ratings for southern leaf blight of maize and days to anthesis (DTA) in two recombinant inbred line (RIL) populations; H99/B73 and B73/B52, consisting of 142 and 186 lines, respectively, scored in 2 years at Clayton, NC. Plants are scored on a scale of 1 to 9 with 1 being complete resistant and 9 being dead. In each case the average scores of the parental lines are indicated. A, WMD for the H99/B73 RIL population. B, WMD for the B73/B52 RIL population. C, DTA for the H99/B73 RIL population. D, DTA for the B73/B52 RIL population.
Field trials. The RIL and parental lines for each population were evaluated for resistance to $\operatorname{SLB}$ (C. heterostrophus race O) and days to anthesis in field trials at North Carolina State University, Central Crops Research Station located at Clayton, NC, in the summers of 2005 and 2006, planted on 21 and 18 April, respectively. Experimental units consisted of $2 \mathrm{~m}$ single-row plots with spacing of $0.97 \mathrm{~m}$ arranged in randomized complete blocks with two replications per year. Twelve seeds per plot were planted and rows were not thinned.

Fungal growth, inoculation, and rating techniques. Individual plants were inoculated at the fourth- to sixth-leaf stage by placing $\approx 20$ grains of a sorghum culture of mixed $C$. heterostrophus isolates in the leaf whorl. Techniques used for inoculum preparation are identical to those reported previously (10).

Ratings. Plants were rated on a plot-basis three times at 14-day intervals in 2005 and four times at 7-day intervals in 2006, at each location. In each case, the first rating was taken approximately at the time of anthesis. Plants were rated in increments of 0.5 on a one to nine semi-quantitative scale as described previously (2). For example, plants with no evidence of leaf blight were rated as 1, plants on which the lesions on the ear leaf had started to coalesce were rated as a 5 and plants that were completely dead were rated as a 9. The number of days after planting when half the plants in the row were shedding pollen was noted as the DTA.

Statistical analyses. SLB resistance in two environments was evaluated in this study (Clayton 2005 and Clayton 2006). Weighted mean disease (WMD) values were calculated for each RIL in each replication in each environment. WMD was calculated by taking the average value of two consecutive ratings and multiplying by the number of days between the ratings. Values were then summed over all the intervals and then adjusted by dividing by the number of days of evaluation, so that the WMD values were on a similar one to nine scale as the initial ratings. WMD ratings are functionally equivalent to area under disease progress curve (AUDPC) ratings and have been called standardized AUDPC ratings in other publications $(7,25)$.

Due to seed shortages and low germination, approximately $2 \%$ of the lines were not included in both replicates in both populations. To account for missing data for subsequent QTL analyses, a least square means of the WMD values across replications per environment was calculated using the PROC GLM procedure of SAS (SAS Institute, Cary, NC). Correlations between replications within an environment and between scores for each environment were high for both WMD and DTA. Therefore least square means across the two environments were used for all QTL analyses. All correlation calculations were made using the PROC CORR procedure of SAS (SAS Institute). Heritability was estimated for each trait using the PROC MIXED procedure of SAS (SAS Institute), as described by Holland et al. (18). PROC MIXED was also used to estimate the variance components attributable to environment, replication within environment, line, and line by

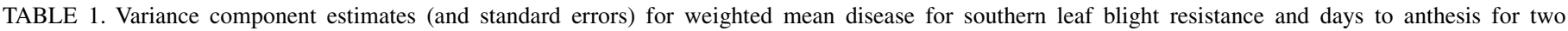
recombinant inbred line populations; H99/B73 and B73/B52, consisting of 142 and 186 lines, respectively, scored in 2005 and 2006 at Clayton, NC

\begin{tabular}{|c|c|c|c|c|c|c|c|c|}
\hline \multicolumn{9}{|c|}{ Variance component estimates (standard error) and $P$ values } \\
\hline \multirow[b]{2}{*}{ Parameter } & \multicolumn{4}{|c|}{ H99/B73 RIL ${ }^{\text {a }}$ population } & \multicolumn{4}{|c|}{ B73/B52 RIL population } \\
\hline & $\mathrm{WMD}^{\mathrm{b}}$ & $P$ value & DTA $^{c}$ & $P$ value & WMD & $P$ value & DTA & $P$ value \\
\hline Environment & $0(-)$ & $\ldots$ & $8.16(11.63)$ & $\mathrm{ns}^{\mathrm{d}}$ & $0(-)$ & $\ldots$ & $2.30(4.19)$ & ns \\
\hline Replication within environment & $0.07(0.06)$ & ns & $0.10(0.11)$ & ns & $0.03(0.03)$ & ns & $1.24(1.25)$ & ns \\
\hline Line & $0.93(0.12)$ & $<0.01$ & $4.07(0.63)$ & $<0.01$ & $0.42(0.05)$ & $<0.01$ & $3.68(0.50)$ & $<0.01$ \\
\hline Environment by line & $0.094(0.03)$ & $<0.01$ & $1.08(0.27)$ & $<0.01$ & $0.058(0.02)$ & $<0.01$ & $0.68(0.19)$ & $<0.01$ \\
\hline Residual & $0.22(0.19)$ & $<0.01$ & $2.02(0.18)$ & $<0.01$ & $0.14(0.01)$ & $<0.01$ & $1.88(0.14)$ & $<0.01$ \\
\hline
\end{tabular}

a Recombinant inbred line.

$\mathrm{b}$ Weighted mean disease.

c Days to anthesis.

${ }^{\mathrm{d}} \mathrm{ns}=$ not significant. 
environment interactions. A mixed models approach using PROC MIXED is more appropriate for dealing with missing data and random effects than is analysis of variance (ANOVA) $(18,23)$.

QTL analyses were performed using MapQTL5 (27). Multiple QTL mapping (MQM mapping, also known as composite interval mapping or CIM) was performed with cofactors initially identified by simple interval mapping and subsequently by initial rounds of MQM mapping. The 95\% threshold level for calling QTL was determined by permutation tests (1,000 permutations in each case). Possible epistatic interactions between the identified QTL were examined using the multiple interval mapping (MIM) of Windows QTL cartographer version 2.5 (28) as described previously (2).

\section{RESULTS AND DISCUSSION}

Population characteristics. H99 and B73, the parents of the HB population, had relatively divergent phenotypes for both DTA (71 days and 79.8 days average, respectively) and WMD (2.8 and 4.4, respectively, Fig. 1A and C). B52 and B73, the parents of the BB population, were relatively similar for both traits (81.2 days and 79.6 days, respectively, for DTA, and 3.9 and 4.3, respectively, for WMD, Fig. 1B and D).

The entry mean narrow sense heritability for WMD and DTA in the $\mathrm{HB}$ population were $0.876(\mathrm{SE}=0.02)$ and $0.761(\mathrm{SE}=0.03)$, respectively. For the $\mathrm{BB}$ population, entry mean narrow sense heritability values were $0.73(0.14)$ and $0.59(0.26)$ for WMD and

TABLE 2. Chromosomal locations and parameters associated with the quantitative trait loci (QTL) for weighted mean disease ratings for southern leaf blight of maize and days to anthesis in two recombinant inbred line populations; H99/B73 and B73/B52, consisting of 142 and 186 lines, respectively, scored in 2 years at Clayton, $\mathrm{NC}$

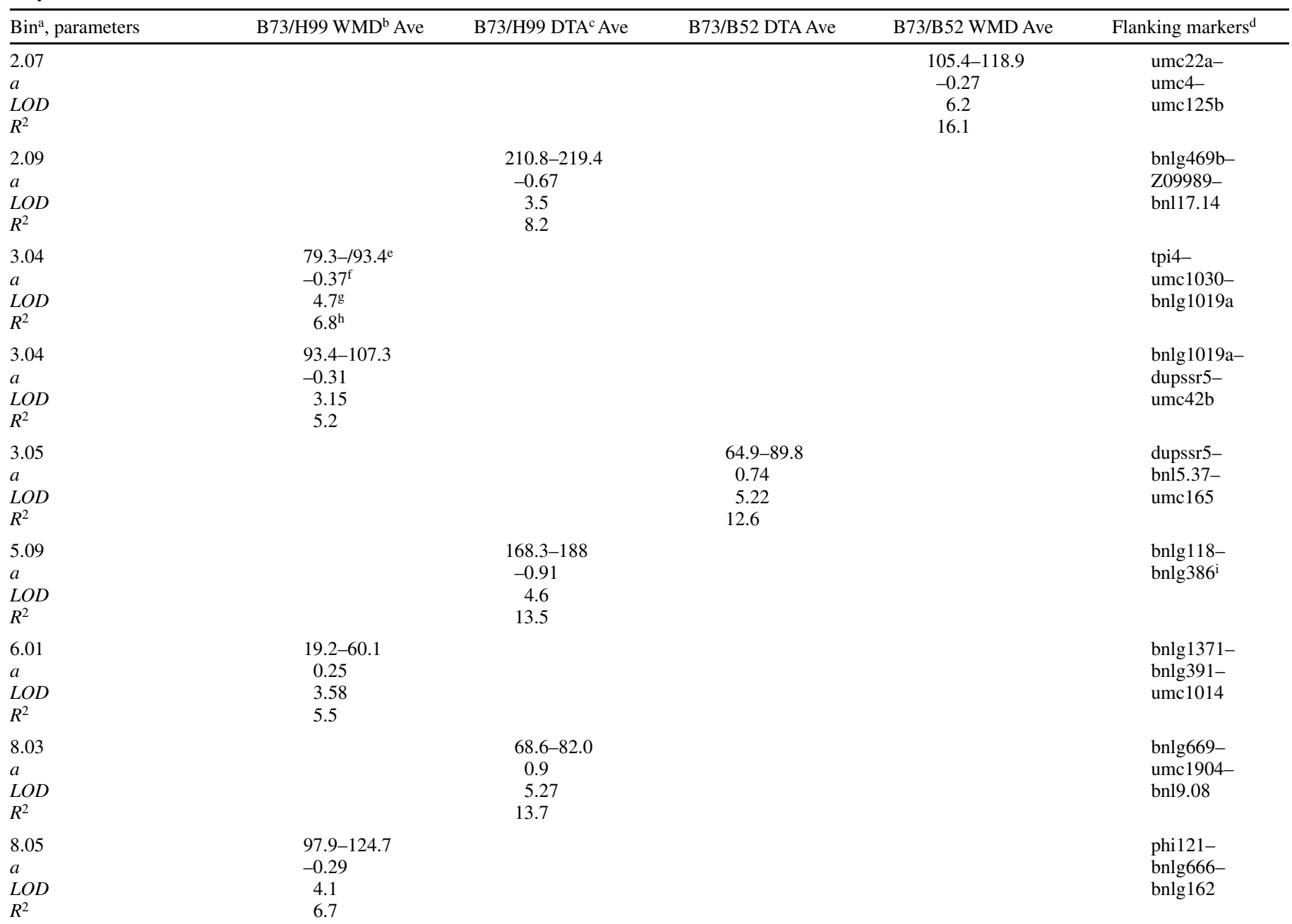

${ }^{a}$ Chromosome bin location of QTL peak on one of the ten chromosomes of the maize genome. Bins divide the genetic map into 100 approximately equal segments. The segments are designated with the chromosome number followed by a two digit decimal (e.g. 1.00, 1.01, 1.02, and so on), Davis et al (12). QTL for overall ratings averaged over replications and years are shown.

$\mathrm{b}$ Weighted mean disease.

${ }^{c}$ Days to anthesis.

${ }^{\mathrm{d}}$ In most cases three markers are listed. The first and third markers flank the two log of odds (LOD) confidence interval, while the middle marker is closest to the LOD peak of the QTL.

e The positions that define the two LOD interval around the position of peak likelihood for the QTL. For the B73/H99 population, the map coordinates are in terms of the B73/H99 RI 2005 map (14). For the B73/B52 RIL population the map coordinates are in terms of the map published in Cardinal et al. (8). The map coordinates of these two populations cannot be directly compared.

${ }^{\mathrm{f}}$ The additive effect of the QTL. For disease ratings, this is in terms of the 1 to 9 scale employed. For DTA, this is terms of days. A positive number indicates that the allele for resistance (or late anthesis) was derived from B73 and a negative number means that the allele for resistance was derived from H99 or B52, depending on the population.

${ }^{\mathrm{g}}$ The LOD value at the position of peak likelihood of the QTL.

${ }^{\text {h }} R^{2}$ estimates the proportion of recombinant inbred line (RIL) mean variance (\%) explained by the detected QTL.

${ }^{i}$ In this case, bnlg386 is the final marker on chromosome 5. The closest marker to the QTL is bnlg386 with bnlg118 marking the proximal 2-LOD boundary. 
DTA, respectively. The Pearson correlation coefficients for both WMD and DTA between replications and between years for each population were relatively high with WMD correlations being consistently higher than DTA correlations. All correlations were highly significant $(P<0.01)$. For the HB population the correlation coefficients between years were 0.85 and 0.65 for WMD and DTA, respectively. For the BB population the correlation coefficients between years were 0.76 and 0.61 for WMD and DTA, respectively. The correlations between average WMD and average DTA phenotypes were not significant with correlation coefficients of 0.01 and 0.12 for the $\mathrm{HB}$ and $\mathrm{BB}$ populations, respectively.

For WMD, line (genotypic) effects were the main significant contributor to phenotypic variance in both populations (Table 1). While environment had a minor effect for WMD, it had a bigger effect on DTA in both populations. However, the standard error of the environment variance estimate for DTA was large and the effects were consequently not significant in both populations. The environmental interaction largely involved differences in degree rather than being a cross-over type of interaction involving changes in rank.
QTL detection. We only report here QTL identified from data averaged over replications and environments (Table 2) due to the fact that for both populations and for both traits, the QTL identified in single environments were similar (data not shown), combined with the relatively high heritabilities and phenotypic correlations observed. In the HB population, two QTL for WMD were detected in bin 3.04 and one each in bins 6.01 and 8.05 (all QTL parameters are detailed in Table 2, for discussion of maize bins see reference 12). In the case of the QTL in bin 6.01, the resistance allele was from B73, the more susceptible parent. At the other three QTL, the resistance allele was inherited from H99. QTL for DTA were detected in bins 2.09, 5.09, and 8.03. Interestingly two QTL alleles for late flowering were derived from H99, which was significantly earlier-flowering than B73, the other parent of the HB population (Figure 1C). An epistatic interaction was detected between the two WMD QTL in bin 3.04, with a partial $\mathrm{R}^{2}$ of 2.2 and an additive effect of 0.23 . No interactions were detected between DTA QTL in the HB population.

In the BB population, one WMD QTL was identified in bin 2.07 with resistance derived from the B52 allele and one DTA

TABLE 3. A comparison of the locations of southern leaf blight quantitative trait loci (QTL) identified in recombinant inbred line populations derived from seven different crosses

\begin{tabular}{|c|c|c|c|c|c|c|c|}
\hline \multirow[b]{2}{*}{$\operatorname{Bin}^{\mathrm{a}}$} & \multicolumn{7}{|c|}{ Cross from which RIL $^{\mathrm{b}}$ population was derived } \\
\hline & $\mathrm{B} 73 / \mathrm{B} 52^{\mathrm{c}}$ & $\mathrm{B} 73 / \mathrm{H} 99^{\mathrm{c}}$ & $\mathrm{B} 73 / \mathrm{Mo} 17^{\mathrm{d}}$ & $\mathrm{B} 104 / \mathrm{NC} 300^{\mathrm{e}}$ & HTI/LTI ${ }^{\mathrm{f}}$ & $\mathrm{B} 73 / \mathrm{NC}^{250 \mathrm{~A}^{\mathrm{g}, \mathrm{h}}}$ & ADENT/B73rhm ${ }^{\mathrm{h}, \mathrm{i}}$ \\
\hline$\underline{\mathbf{1 . 0 3}}$ & & & B73 & & & & \\
\hline 1.06b & & & Mo17 & & & & \\
\hline 1.07 & & & Mo17 & & & & \\
\hline$\underline{1.08 / 09}$ & & & Mo17 & NC300 & & NC250A & \\
\hline $2.06 / 07$ & B52 & & & NC300 & & & \\
\hline$\overline{2.09}$ & & & B73 & & & & \\
\hline 3.04a & & H99 & Mo17 & NC300 & LTI & NC250 & B73 \\
\hline 3.04b & & H99 & B73 & & & & \\
\hline 3.06 & & & Mo17 & & & & \\
\hline$\overline{3.07 / 08}$ & & & & B104 & & & \\
\hline$\overline{3.08 / 09}$ & & & & NC300 & & & B73 \\
\hline 6.01 & & B73 & Mo17 & & & NC250A & B73 \\
\hline 6.02 & & & B73 & & & & \\
\hline 6.06 & & & & NC300 & & & \\
\hline$\overline{7.02}$ & & & B73 & & & NC250A & \\
\hline 7.03 & & & B73 & & & & \\
\hline$\overline{8.02 / 03}$ & & & Mo17 & & & & \\
\hline 8.05 & & H99 & & & & & B73 \\
\hline$\overline{9.03 / 04}$ & & & & NC300 & & NC250A & \\
\hline $\mathbf{1 0 . 0 6 / 0 7}$ & & & Mo17 & & & & \\
\hline
\end{tabular}

${ }^{\text {a }}$ Chromosome bin location of QTL peak on one of the ten chromosomes of the maize genome. Bins divide the genetic map into 100 approximately equal segments. The segments are designated with the chromosome number followed by a two digit decimal (e.g., 1.00, 1.01, 1.02, and so on), Davis et al. (12). In each case where a QTL was detected in a specific bin, the identity of the line from which resistance is derived is shown. Bold font indicates that the resistance QTL explained more than $5 \%$ of the total phenotypic variation.

${ }^{\mathrm{b}}$ Recombinant inbred line.

c This study.

${ }^{\mathrm{d}}$ Balint-Kurti and Carson (1), Balint-Kurti et al. (3), and Carson et al. (10). These studies report QTL identified in field studies as well as in greenhouse studies on juvenile maize.

e Balint-Kurti et al. (2).

${ }^{\mathrm{f}}$ Highland tropical inbred/Lowland tropical inbred (21).

$\mathrm{g}$ In this study two $\mathrm{F}_{2: 3}$ populations derived from very similar crosses-B73/NC250A and B73rhm/NC250A (B73rhm is a near-isogenic derivative of B73 carrying the rhm gene for SLB resistance) were examined. For the sake of simplicity we are reporting the QTL identified in the overall analysis of both populations (4).

h This study was carried out in 1990 before molecular markers that comprehensively covered the maize genome were available. Therefore the maps consist of only $\approx 80$ markers and QTL are poorly defined compared to more modern studies and the confidence intervals often span several bins. In cases where this occurs, we have assigned the QTL to the most probable bins.

${ }^{i}$ An $F_{2: 3}$ population derived from and ADENT/B73rhm cross (4). ADENT is an inbred line derived from the cross Amario Dentado 2//A632/B14A/3/Amario Dentado 2. Amarillo Dentado is a synthetic population developed at the International Maize and Wheat Improvement Center (CIMMYT, Mexico).

j In the cases where two QTL were detected in the same bin the QTL are differentiated by 'a' and 'b' suffixes. 
QTL was identified in bin 3.05 with late flowering conferred by the B73 allele.

SLB, like other necrotrophic foliar diseases of maize such as grey leaf spot (causal agent Cercospora zeae-maydis) and anthracnose leaf blight (causal agent Colletotrichum graminicola, is generally a late-season disease, with most disease development occurring post-anthesis (30). Thus there is concern that disease ratings might be affected by variations between lines in time to maturity. In the present study, as in previous SLB studies, no significant correlation was observed between disease rating and time to anthesis, nor were there any shared QTL for flowering and disease traits.

The BB population has also been used to map QTL for European corn borer (Ostrinia nubilalis [Hübner]) resistance (8) and fiber and lignin content (9). The single SLB resistance QTL identified in this population in bin 2.07 maps precisely to a region associated with both European corn borer resistance (8) and fiber content in leaf sheaths and stalks (9). The causal agent of SLB, the fungus Cochliobolus hetrostrophus usually penetrates the leaf directly through the cuticle at junctions between epidermal cells and starts to grow intracellularly within a few days of infection $(17,20,29)$. While the correspondence of the QTL in 2.07 between the two studies could certainly be coincidental, it is possible that variation in fiber content could contribute to SLB resistance by affecting the resistance of plant cell walls to penetrating fungal hyphae.

A summary of SLB QTL studies. Including this study, SLB resistance QTL have now been identified in eight separate segregating populations. Two of these populations shared the same parents (B73 and Mo17); therefore populations derived from seven different crosses have been examined. Table 3 compares the locations of SLB resistance QTL identified in populations derived from these seven crosses, five of which include B73 as one of the parents. In several cases, SLB resistance QTL are found in the same bin in populations derived from two or more different crosses. At least one SLB resistance QTL was identified in bin 3.04 in all the populations examined with the exception of the B73/B52 population. Bin 3.04 has also been noted as a 'hot-spot' for genes for viral resistance (24,31). Looking specifically at the HB and B73/ Mo17 populations, for the distal QTL in bin 3.04, resistance was derived from the non-B73 parent in both cases (Table 3). However for the proximal QTL, resistance was derived from the non-B73 parent (H99) in the HB population while it was derived from B73 in the B73/Mo17 population. It is possible that an allelic series exists at this locus with the H99 allele providing more resistance than the B73 allele, which in turn provides more resistance than the Mo17 allele.

An SLB resistance QTL was identified in bin 6.01 in four of the crosses examined (Table 3 ). The rhm gene, which confers almost complete SLB resistance in pre-anthesis growth stages and a partial level of resistance post-anthesis, is also located in or near bin $6.01(11,26,32)$. It seems likely that the QTL identified in this region may be conferred by a series of alleles of the $\mathrm{rhm}$ gene. In addition to bin 3.04 previously mentioned, bin 6.01 also appears to be a hot-spot for viral disease resistance genes $(24,31)$.

Fine-mapping of selected QTL described here, combined with the genomic sequence of B73 that will be available by the end of 2008 , should facilitate the eventual identification of genes underlying quantitative resistance to SLB.

\section{ACKNOWLEDGMENTS}

We thank R. Wisser for help with phenotyping and editing the final manuscript and J. Holland for statistical advice. We also appreciate help from the following with aspects of the research: R. Baesman, D. Stephens, S. Wang, C. Yencho, C. Herring, and the staff of the Central crops research Station, Clayton, NC. This work was funded by the USDA-ARS and by a grant from the CGIAR Generation Challenge Program.

\section{LITERATURE CITED}

1. Balint-Kurti, P. J., and Carson, M. L. 2006. Analysis of quantitative trait loci for resistance to southern leaf blight in juvenile maize. Phytopathology 96:221-225.

2. Balint-Kurti, P. J., Krakowsky, M. D., Jines, M. P., Robertson, L. A., Molnár, T. L., Goodman, M. M., and Holland, J. B. 2006. Identification of quantitative trait loci for resistance to southern leaf blight and days to anthesis in a maize recombinant inbred line population. Phytopathology 96:1067-1071.

3. Balint-Kurti, P. J., Zwonitzer, J. C., Wisser, R. J., Carson, M. L., OropezaRosas, M., Holland, J. B., and Szalma, S. J. 2007. Precise mapping of quantitative trait loci for resistance to southern leaf blight, caused by Cochliobolus heterostrophus race $\mathrm{O}$, and flowering time using advanced intercross maize lines. Genetics 176:645-657.

4. Bubeck, D. M. 1991. Molecular and biometric evaluation of gray leaf spot and southern corn leaf blight resistance in maize. Ph.D. Thesis, Dept. of Crop Science. North Carolina State University, Raleigh, NC.

5. Burnette, D. C., and White, D. G. 1985. Inheritance of resistance to Bipolaris maydis race $\mathrm{O}$ in crosses derived from nine resistant inbred lines of maize. Phytopathology 75:1195-1200.

6. Byrnes, K. J., Pataky, J. K., and White, D. G. 1989. Relationships between yield of three maize hybrids and severity of southern leaf blight caused by race O of Bipolaris maydis. Plant Dis. 73:834-840.

7. Campbell, C. L., and Madden, L. V. 1990. Pages 192-194 in: Introduction to Plant Disease Epidemiology. John Wiley and Sons, New York.

8. Cardinal, A. J., Lee, M., and Moore, K. 2003. Genetic mapping and analysis of quantitative trait loci affecting fiber and lignin content in maize. Theor. Appl. Genet. 106:866-874.

9. Cardinal, A. J., Lee, M., Sharopova, N., Woodman-Clikeman, W. L., and Long, M. J. 2001. Genetic mapping and analysis of quantitative trait loci for resistance to stalk tunneling by the European corn borer in maize. Crop Sci. 41:835-845.

10. Carson, M. L., Stuber, C. W., and Senior, M. L. 2004. Identification and mapping of quantitative trait loci conditioning resistance to southern leaf blight of maize caused by Cochliobolus heterostrophus race $\mathrm{O}$. Phytopathology 94:862-867.

11. Chang, R. Y., and Peterson, P. A. 1995. Genetic control of resistance to Bipolaris maydis: One gene or two genes? J. Hered. 86:94-97.

12. Davis, G. L., McMullen, M. D., Baysdorfer, C., Musket, T., Grant, D., Staebell, M., Xu, G., Polacco, M., Koster, L., Melia-Hancock, S., Houchins, K., Chao, S., and Coe, E. H., Jr. 1999. A maize map standard with sequenced core markers, grass genome reference points and 932 expressed sequence tagged sites (ESTs) in a 1736-locus map. Genetics 152:1137-1172.

13. Fisher, D. E., Hooker, A. L., Lim, S. M., and Smith, D. R. 1976. Leaf infection and yield loss caused by 4 Helminthosporium leaf diseases of corn. Phytopathology 66:942-944.

14. Frascaroli, E., Canè, M. A., Landi, P., Pea, G., Gianfranceschi, L., Villa, M., Morgante, M., and Pè, M. E. 2007. Classical genetic and QTL analyses of heterosis in a maize hybrid between two elite inbred lines. Genetics 176:625-644.

15. Frova, C., Krajewski, P., di Fonzo, N., Villa, M., and Sari-Gorla, M. 1999. Genetic analysis of drought tolerance in maize by molecular markers. Theor. Appl. Genet. 99:280-288.

16. Gregory, L. V., Ayers, J. E., and Nelson, R. R. 1979. The influence of cultivar and location on yield loss in corn (Zea mays) due to southern corn leaf blight Helminthosporium maydis. Plant Dis. Rep. 63:891-895.

17. Hilu, H. M., and Hooker, A. L. 1965. Localized infection by Helminthosporium turcicum on corn leaves. Phytopathology 55:189-192.

18. Holland, J. B., Nyquist, W. E., and Cervantes-Martinez, C. T. 2003. Estimating and interpreting heritability for plant breeding: An update. Plant Breed. Rev. 22:9-112.

19. Holley, R. N., and Goodman, M. M. 1989. New sources of resistance to southern corn leaf blight from tropical hybrid maize derivatives. Plant Dis. 73:562-564.

20. Jennings, P. R., and Ulstrup, A. J. 1957. A histological study of three Helminthosporium leaf blights of corn. Phytopathology 47:707-714.

21. Jiang, J. C., Edmeades, G. O., Armstead, I., Lafitte, H. R., Hayward, M. D., and Hoisington, D. 1999. Genetic analysis of adaptation differences between highland and lowland tropical maize using molecular markers. Theor. Appl. Genet. 99:1106-1119.

22. Lim, S. M., and Hooker, A. L. 1976. Estimates of combining ability for resistance to Helminthosporium maydis race $\mathrm{O}$ in a maize population. Maydica 21:121-128.

23. Littell, R. C., Milliken, G. A., Stroup, W. A., and Wolfinger, R. D. 1996. SAS System for mixed models. SAS Institute, Cary, NC.

24. McMullen, M. D., and Simcox, K. D. 1995. Genomic organization of disease and insect resistance genes in maize. Mol. Plant-Microbe Interact. 8:811-815. 
25. Shaner, G., and Finney, P. E. 1977. The effect of nitrogen fertilizer on expression of slow mildewing resistance in Knox wheat. Phytopathology 67:1051-1056.

26. Thompson, D. L., and Bergquist, R. R. 1984. Inheritance of mature plant resistance to Helminthosporium maydis race 0 in maize. Crop Sci. 24:807-811.

27. Van Ooijen, J. W. 2004. MapQTL 5, Software for the mapping of quatitative trait loci in experimental population. B. V. Kyazma, Wageningen, the Netherlands.

28. Wang, S., Basten, C. J., and Zeng, Z. B. 2004. Windows QTL Cartographer 2.0. 2001-2004, Department of Statistics, North Carolina
State University, Raleigh, NC.

29. Wheeler, H. 1977. Ultrastructure of penetration by Helminthosporium maydis. Physiol. Plant Pathol. 11:171-178.

30. White, D. G., ed. 1999. Compendium of Corn Diseases. 3rd ed. The American Phytopathological Society, St. Paul, MN.

31. Wisser, R. J., Balint-Kurti, P. J., and Nelson, R. J. 2006. The genetic architecture of disease resistance in maize: A synthesis of published studies. Phytopathology 96:120-129.

32. Zaitlin, D., Demars, S., and Ma, Y. 1993. Linkage of rhm, a recessive gene for resistance to southern corn leaf blight, to RFLP marker loci in maize (Zea mays) seedlings. Genome 36:555-564. 